\title{
The challenges of hand hygiene improvement: a comparison between inpatient and outpatient units
}

\author{
JY Kawagoe ${ }^{1 *}$, CV Silva ${ }^{1}$, MF Cardoso ${ }^{1}$, P Gonçalves ${ }^{1}$, MG Ballalai ${ }^{1}$, AR Toniolo ${ }^{1}$, CB DalForno ${ }^{1}$, ST Valerio², \\ EAA Reis ${ }^{3}$, LG Pontes $^{1}$, LB Cunha ${ }^{2}$, L Correa $^{1}$ \\ From International Conference on Prevention \& Infection Control (ICPIC 2011) \\ Geneva, Switzerland. 29 June - 2 July 2011
}

\section{Introduction / objectives}

WHO Hand Hygiene (HH) Improvement Strategy Program has been implemented mostly in inpatient units. We implemented this strategy in inpatient and outpatient units.

\section{Objective}

Compare the results of $\mathrm{HH}$ adherence in inpatient and outpatient units.

\section{Methods}

This program was conducted in a 500-bed private hospital in São Paulo, Brazil. WHO tool was used to assess $\mathrm{HH}$ adherence before (Jun-Aug2008) and after the intervention (Jul-Sept2009). The inpatient units were: Medical Surgical Ward, Oncology, Neonatal and Pediatrics and outpatient were: Surgical Ambulatory, Obstetric Center, Emergency, Post Anesthesia, Diagnostic Medicine Department and Dialysis Center. Several strategies were applied - campaigns, behavioral methods, and educational programs. More dispensers of alcohol-based product were made available in areas of the hospital such as restaurants, cafeterias, waiting rooms, lounges, receptions and next to elevators.

\section{Results}

In inpatient units the overall $\mathrm{HH}$ adherence improved $30.8 \%$, from $63.8 \%$ (1433/2248 opportunities) to $83.5 \%$ $(2144 / 2567$ opportunities). In outpatient units it improved $53.2 \%$, from $39.5 \%$ (679/1721 opportunities) to $60.4 \%(1044 / 1728$ opportunities). The only exception in $\mathrm{HH}$ improvement was physician (no increase in inpatient unit) and Obstetric Center (5\% decrease).

\section{Conclusion}

The higher compliance was in inpatient units, although there was a significant improvement in outpatient units. We must develop and apply different strategies according to the needs of inpatient and outpatient units.

\section{Disclosure of interest}

None declared.

\section{Author details}

${ }^{1}$ Infection Prevention and Control Service, São Paulo, Brazil. ${ }^{2}$ Education and Research Institute, São Paulo, Brazil. ${ }^{3}$ Patient Safety, Hospital Albert Einstein, São Paulo, Brazil.

Published: 29 June 2011

doi:10.1186/1753-6561-5-S6-P110

Cite this article as: Kawagoe et al:: The challenges of hand hygiene improvement: a comparison between inpatient and outpatient units. BMC Proceedings 2011 5(Suppl 6):P110.

${ }^{1}$ Infection Prevention and Control Service, São Paulo, Brazil

Full list of author information is available at the end of the article

(c) 2011 Kawagoe et al; licensee BioMed Central Ltd. This is an open access article distributed under the terms of the Creative 